\title{
ChemComm
}

\section{Unprecedented participation of a four-coordinate hydrogen atom in the cubane core of lithium and sodium phenolates $t$}

\author{
Cite this: Chem. Commun., 2013 \\ 49, 11809 \\ Received 27th September 2013, \\ Accepted 23rd October 2013
}

DOI: $10.1039 / \mathrm{c3cc47393g}$

\author{
David M. Cousins, Matthew G. Davidson* and Daniel García-Vivó*
}

www.rsc.org/chemcomm

Metalation of an ammonium tris(phenol) ligand affords new lithium/
sodium derivatives having central pseudocubane motifs in which one of
the metallic positions is replaced by a four-coordinate hydrogen atom.

Periodic trends in the chemical properties of elements are one of the most important and better established concepts in chemistry. ${ }^{1}$ They are elegantly represented in the Periodic table, which provides a visual representation of the connection between atomic number, electronic structure and group relationships. One of the best examples of group trends is found for the alkali metals which exhibit well-defined changes in their atomic properties. ${ }^{1}$ However, the position of hydrogen as the first element of Group 1 is a question which is still open to debate. Undoubtedly, the similarity of the electronic structure of $\mathrm{H}\left(1 \mathrm{~s}^{1}\right)$ with that of the alkaline elements $\left(n s^{1}\right)$ is not, at least obviously, translated into a similarity in the properties of these elements (i.e. under ambient conditions the former is a diatomic gas and the latter are solid metals). In spite of this, over the years a close relationship between hydrogen and the light elements in the group (mainly Li) has been discerned in two respects. First, under extreme conditions, hydrogen can exhibit "metallic" properties typical of the alkali metals ${ }^{2}$ and, secondly, lithium has been attributed H-like characteristics. Thus, while hydrogen has been known for decades to participate in secondary interactions known as "hydrogen bonds" the analogous "lithium bond" was first suggested in $1958^{3}$ and predicted theoretically by Kollman et al. in $1970 .^{4}$ Since then the analogy has been generally accepted and "lithium bonds" have been the basis of many theoretical and spectroscopic investigations. ${ }^{5}$ These similarities are not only important for a better understanding of fundamental chemical principles, but have also recently received attention in organocatalysis, after considering that hydrogen atoms can perform the role of Lewis acidic metal centres. ${ }^{6}$

Centre for Sustainable Chemical Technologies, Department of Chemistry,

University of Bath, Claverton Down, Bath, BA2 7AY, UK.

E-mail: m.g.davidson@bath.ac.uk,garciavdaniel@uniovi.es

† Electronic supplementary information (ESI) available: Full experimental details, including spectroscopic data for new compounds. CCDC 916821-916824. For ESI and crystallographic data in CIF or other electronic format see DOI: 10.1039/c3cc47393g
Given these similarities, as well as recent advances in synthetic methodology, and the plethora of organic and metal-organic crystal structure data available, an obvious question to ask is why have hydrogen and the alkali metals rarely, if ever, been observed to perform the same structural role in a molecular crystal structure?

One answer to this question lies in the difference in size which leads to very different structural preferences (Chart 1). Thus, the smaller $\mathrm{H}$ atom, when covalently bonded to an electronegative atom, has a strong preference for a nearly linear two-centre secondary interaction with another electronegative centre. Higher coordination numbers are possible via additional secondary interactions, although the occurrence of three-centre hydrogen bonds (bifurcated) is less common and four-centre (trifurcated) hydrogen bonds are rarely observed in organic crystals (Chart 1). ${ }^{7}$ By comparison, heavier Group 1 elements are larger atoms which can easily accommodate higher coordination numbers and they almost exclusively participate in three and four-centre interactions via either association (oligomers), coordination of neutral donor ligands (solvation) or commonly by a combination of both (Chart 1). ${ }^{8}$ As a result, one of the most common structural motifs for these elements is the solvated pseudocubane.

In order to induce a structural equivalence of $\mathrm{H}$ and the alkali metals, one approach might be using a ligand framework combining the preference for association into the pseudocubane structural motif with the ability to force $\mathrm{H}$ into a trifurcated bonding mode. Overcoming the fundamental structural differences in this way would provide the opportunity for $\mathrm{H}$ to participate in a molecular metallic array typical of the alkali metals (behaving as an alkali metal structurally). As part of our studies of metal complexes of

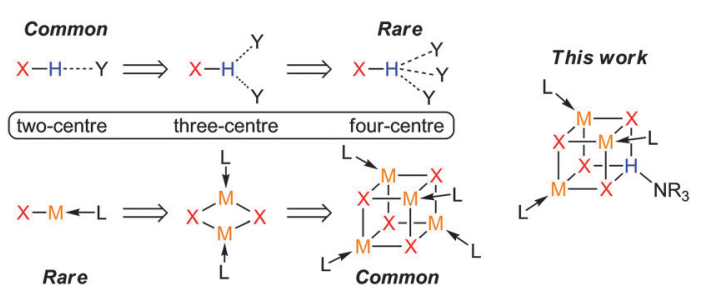

Chart 1 Typical structural motifs for hydrogen (top) and Li/Na (bottom). 


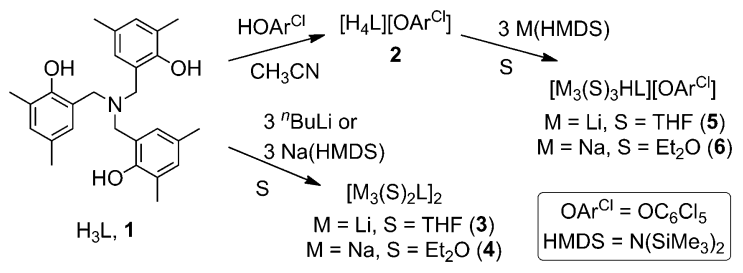

Scheme 1 Synthesis of new compounds.

triphenolamines (Scheme 1), ${ }^{9}$ here we report the synthesis and characterisation of multi-lithiated and multi-sodiated derivatives of these ligands which display some unique structural features. This includes the first examples of complexes in which a $\mathrm{H}$ atom participates in the pseudocubane motif typical of $\mathrm{Li} / \mathrm{Na}$ aryloxides ${ }^{8,10}$ by replacing one of the metallic positions, proving for the first time that a structural equivalence between these elements is indeed possible.

The neutral tris(phenol) ligand $\mathbf{1}$ (Scheme 1) is readily prepared in high yield following protocols provided in the literature. ${ }^{11}$ Addition of one equivalent of an acidic enough phenol, such as pentachlorophenol $\left(\mathrm{HOAr}^{\mathrm{Cl}}\right)$, to acetonitrile solutions of $\mathbf{1}$ immediately induces the precipitation of the corresponding ammonium phenolate ligand, $\left[\mathrm{H}_{4} \mathrm{~L}\right] \mathrm{OAr}^{\mathrm{Cl}}(2)$, as a white solid in quantitative yield. Ligand 2 has been characterized by comparing its NMR data with that available for the crystallographically characterized chloride salt $\left[\mathrm{H}_{4} \mathrm{~L}\right] \mathrm{Cl}^{12}$ A common feature of these two salts is the appearance of highly deshielded resonances in their ${ }^{1} \mathrm{H}$ NMR spectra [9.28 (Cl) vs. 9.32 (2) ppm], corresponding to the $\mathrm{N}-\mathrm{H}$ group, a feature which remains unaltered in the metallated derivatives of $\mathbf{2}$ as discussed later on.

We then turned our attention to the synthesis of alkali metal derivatives of these two ligands. Although the tri(lithium) and tri(sodium) derivatives of $\mathbf{1}$ have recently been prepared and used (in situ) as starting materials for the preparation of a variety of transition-metal derivatives of $\mathbf{1},{ }^{13}$ no structural characterization has been reported so far for these compounds. The synthesis of these complexes was achieved by addition of three equivalents of ${ }^{n} \mathrm{BuLi}$ or NaHMDS (HMDS $\left.=\mathrm{N}\left(\mathrm{SiMe}_{3}\right)_{2}\right)$ to THF (Li) or $\mathrm{Et}_{2} \mathrm{O}(\mathrm{Na})$ solutions of $\mathbf{1}$, thereby yielding the trimetallated derivatives, $\left[\mathrm{M}_{3}(\mathrm{~S})_{2} \mathrm{~L}\right]_{2}\left[\mathrm{M}=\mathrm{Li}, \mathrm{S}=\operatorname{THF}(3) ; \mathrm{M}=\mathrm{Na}, \mathrm{S}=\mathrm{Et}_{2} \mathrm{O}\right.$ (4)] (Scheme 1), in good yields. X-ray quality crystals of both compounds were obtained from such solutions on cooling (see ESI $\dagger$ ).

The molecular structures of complexes 3 and $\mathbf{4}$ (ESI $\dagger$ and Fig. 1) consist of a distorted face sharing double cubane. Corner-positioned metals are coordinated with three $\mu_{3}-\mathrm{O}$ atoms and a solvent molecule, completing the archetypal slightly distorted tetrahedral geometry around them [angles $\mathrm{O}-\mathrm{M}_{\mathrm{th}}-\mathrm{O} 91.3-132.1^{\circ}$ (3), 88.1-143.7 ${ }^{\circ}$ (4)]. In contrast, the metal atoms belonging to the shared face are fivecoordinate, with two $\mathrm{M}-\left(\mu_{3}-\mathrm{O}\right)$, two $\mathrm{M}-\left(\mu_{4}-\mathrm{O}\right)$ and one $\mathrm{M}-\mathrm{N}$ linkages, defining a square pyramidal geometry with a sum of basal plane angles of $358.9^{\circ}(3), a v \cdot 360.2^{\circ}(\mathrm{Na})$, and a range of basal to apical angles of $91.5-95.7^{\circ}$ (3) and 79.0-97.8 (4). The corresponding $\mathrm{M}-\mathrm{O}$ and $\mathrm{M}-\mathrm{N}$ lengths in complexes $\mathbf{3}$ and $\mathbf{4}$ are unexceptional, in fact quite similar to those previously reported for related $\mathrm{Li}^{14} \mathrm{or} \mathrm{Na}^{15}$ phenoxide cubanes (M-O), or amine bis(phenolate) complexes $(\mathrm{M}-\mathrm{N}) \cdot{ }^{15 e}$ However, both compounds display one significantly elongated M-O bond, 2.227(5) $(\mathrm{Li} 3-\mathrm{O} 3)$ and 2.530(3) $\AA$ (Na8-O4), with these figures being approximately 0.2 and $0.15 \AA$ longer than those typically found in other aryloxide cubanes. ${ }^{14,15}$ Such an effect might

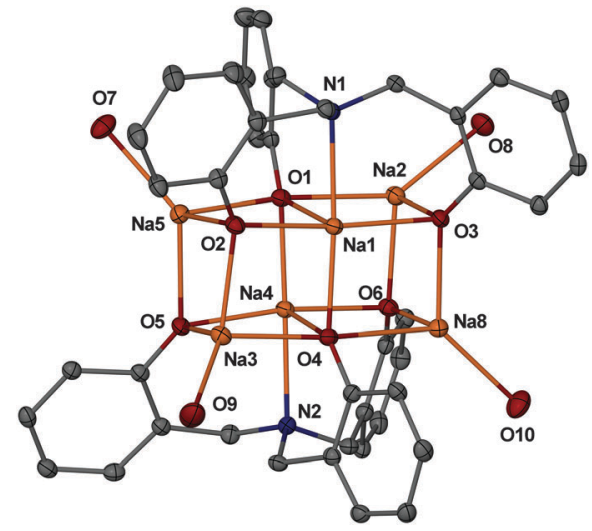

Fig. 1 View of the molecular structure of $\mathbf{4}$ (30\% probability) with hydrogens, methyl and ethyl groups omitted.

be imposed by the rigid nature of the arms in the tris(phenolate) ligands. Moreover, the corner-positioned metals in these two complexes are further stabilized by the presence of short $\mathrm{M} \cdots \mathrm{C}(\mathrm{ipso})$ and $\mathrm{M} \cdots \mathrm{CH}_{3}$ intramolecular interactions, which are similar to those previously found by us for simple $\mathrm{Li}$ and $\mathrm{Na}$ aryloxide complexes supported by polyamine ligands. ${ }^{16}$ Incidentally, complex 3 seems to be the first lithium phenolate complex displaying a face-sharing double cubane structural motif to be crystallographically characterized. Finally, the available NMR data for complexes 3 and $\mathbf{4}$ are essentially consistent with the solid-state structures, but support the presence of fluxional processes in solution which exchange the environments of the metals and hydrocarbon chains through open structures (see ESI $\dagger$ ).

Keeping in mind that the ligand framework provided by the amine(trisphenol) is flexible enough to accommodate $\mathrm{Li}$ and $\mathrm{Na}$ cubanes, we turned our attention to the more challenging metallation of the protonated ligand $2 ;{ }^{17}$ this requires the deprotonation of three $\mathrm{O}-\mathrm{H}$ groups, while leaving the $\mathrm{N}-\mathrm{H}$ group untouched. Somewhat surprisingly, this was easily accomplished by addition of three equivalents of MHMDS [M $=\mathrm{Li}$ and Na] to THF (Li) or $\mathrm{Et}_{2} \mathrm{O}(\mathrm{Na})$ solutions of 2, with the new tri-metallated complexes (5 and 6 in Scheme 1) then isolated in good yields as crystalline materials and characterized by X-ray crystallography and multinuclear NMR. ${ }^{18}$

In the solid state, complexes 5 and $\mathbf{6}$ (Fig. 2 and ESI $\dagger$ ) display a zwitterionic ammonium phenolate ligand of approximate $C_{3}$-symmetry and geometry similar to those previously found in the structures of metal derivatives. ${ }^{9 a, 19}$ The $\mathrm{M}-\mathrm{O}$ distances within these complexes are only marginally shorter than those found for 3 and 4, probably reflecting a less constrained coordination of the tris(phenolate) ligands. The triangle formed by the three metals is capped by the $\mu_{3}$-oxygen atom of the $\mathrm{OAr}^{\mathrm{Cl}}$ group, which is less tightly bound. Each metal is further coordinated with one solvent molecule completing a distorted tetrahedral geometry. In addition, we note the presence of short intramolecular $\mathrm{M} \cdots \mathrm{Cl}$ interactions. In fact, the strongest of these interactions in $\mathbf{5}$ (Li3-Cl5 2.716(2) ̊) is only slightly longer than that found for a Li cation coordinated with a haloalkane $(2.64 \AA) .{ }^{20}$

More intriguing is the role of the central proton which is involved in an unusual trifurcated $\mathrm{NH} \cdots \mathrm{O}_{3}$ hydrogen bond (mean $\mathrm{H}(1)-\mathrm{O}$ lengths 2.18 (5) and $2.32(6) \AA$ ). Thus, the cores of these complexes define a distorted cubane motif with the $\mathrm{H}$ atoms occupying one of 


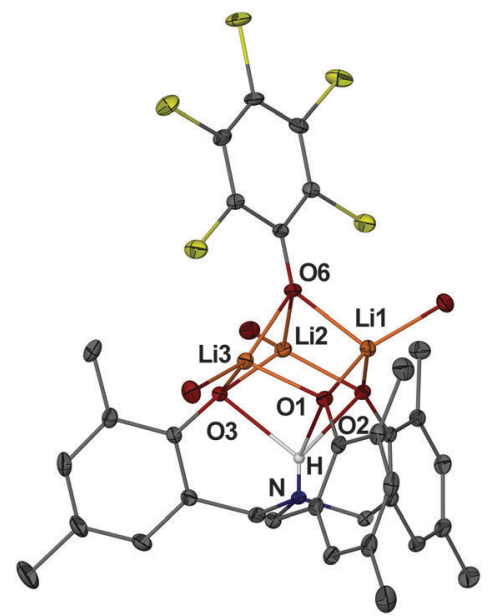

Fig. 2 Solid state structure of $\mathbf{5}$ with most $\mathrm{H}$ atoms and solvent molecules (except $\mathrm{O}$ atoms) omitted. The central $\mathrm{N}-\mathrm{H}$ atom was located in the difference Fourier map and refined isotropically.
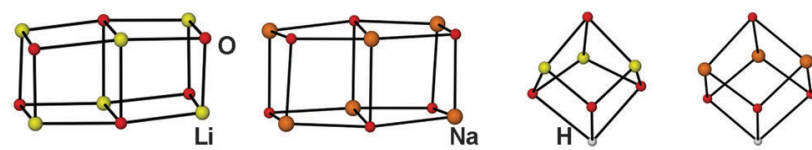

Fig. 3 Central cores in complexes 3-6 (from left to right)

the corner positions (Fig. 3), and therefore effectively replacing one of the metal positions of a typical $\mathrm{Li} / \mathrm{Na}$ aryloxide cubane. To the best of our knowledge, the structures of complexes $\mathbf{5}$ and $\mathbf{6}$ prove for the first time that a hydrogen atom is capable of replacing an alkali metal atom in a typical alkali metal structural motif. In fact, by comparing the cores of complexes 3-6 (Fig. 3) it is clear that the $\mathrm{Li} / \mathrm{Na}$ to $\mathrm{H}$ replacement does not impose significant modifications of the cubane motifs.

Spectroscopic data obtained from solutions of crystalline samples of complexes 5 and $\mathbf{6}$ are consistent with the retention of "monomeric" cubane structural motifs found in the solid state, and with the pseudo $C_{3}$-symmetry exhibited by the ligand framework (assuming free rotation for the $\mathrm{OAr}^{\mathrm{Cl}}$ group). Thus, the ${ }^{7} \mathrm{Li}\left\{{ }^{1} \mathrm{H}\right\} \mathrm{NMR}$ spectrum of 5 exhibits only one resonance $\left(\delta_{\mathrm{Li}}=-0.89 \mathrm{ppm}\right)$, while the ${ }^{1} \mathrm{H}$ NMR spectra of both complexes display just one set of signals for the aromatic protons of the equivalent phenolate rings, along with the expected $A B$ multiplet for three equivalent methylenic $\left(\mathrm{NCH}_{2}\right)$ groups. The retention of the $\mathrm{N}-\mathrm{H}$ bond in solution is clearly supported by the appearance of quite deshielded resonance $\left[\delta_{\mathrm{H}}=\right.$ 12.7 (5), $11.6 \mathrm{ppm}(\mathbf{6})]$ values, which are even higher than that found for the free ligand 2 , probably reflecting the existence of stronger $\mathrm{NH} \cdots \mathrm{O}_{3}$ interactions in these metallated derivatives in solution.

In summary, we have reported for the first time the structural characterization of multi-metallated Group 1 derivatives of amine tris(phenolate) ligands, including the unprecedented participation of a metal-like hydrogen atom in the cubane core of an alkali metal (Li or Na) phenolate. We are now exploring the possibility of extending such a structural analogy to other related systems such as mixed-cubanes with different metals or anions.

We gratefully acknowledge the EPSRC (DTA studentship to D.M.C.), and the European Commission for financial aid (Marie Curie IEF fellowship to D.G.-V., PIEF-2009-235173).

\section{Notes and references}

1 N. N. Greenwood and A. Earnshaw, Chemistry of the Elements, Elsevier, Oxford, 1997.

2 (a) I. F. Silvera and J. W. Cole, J. Phys.: Conf. Ser., 2010, 215, 12194; (b) M. I. Eremets and I. A. Troyan, Nat. Mater., 2011, 10, 927; (c) F. Hensel and P. P. Edwards, Chem.-Eur. J., 1996, 2, 1201.

3 A. N. Rodionov, D. N. Shigorin, T. V. Talalaeva and K. A. Kocheshkov, Dokl. Akad. Nauk SSSR, 1958, 123, 113.

4 P. Kollman, J. Liebman and L. C. Allen, J. Am. Chem. Soc., 1970, 92, 1142.

5 (a) S. Scheiner, in Lithium Chemistry: A Theoretical and Experimental Overview, ed. A. M. Sapse and P. Von R. Schleyer, Wiley Interscience, New York, London, Sydney, 1996, ch. 3; (b) Y. Feng, L. Liu, J.-T. Wang, X.-S. Li and Q.-X. Guo, Chem. Commun., 2004, 88.

6 (a) P. M. Pihko, Angew. Chem., Int. Ed., 2004, 43, 2062; (b) C. Bolm, T. Rantanen, I. Schiffers and L. Zani, Angew. Chem., Int. Ed., 2005, 44, 1758; (c) H. Yamamoto and K. Futatsugi, Angew. Chem., Int. Ed., 2005, 44, 1924; (d) M. S. Taylor and E. N. Jacobsen, Angew. Chem., Int. Ed., 2006, 45, 1520.

7 (a) T. Steiner, Angew. Chem., Int. Ed., 2002, 41, 48; (b) C. Pimentel and A. L. McClellan, The Hydrogen Bond, Freeman, San Francisco, 1960; (c) F. Renaud, C. Piguet, G. Bernardinelli, J.-C. G. Bünzli and G. Hopfgartner, J. Am. Chem. Soc., 1999, 121, 9326.

8 For some reviews in the structural chemistry of organocomplexes of alkali metals see: $(a)$ W. N. Setzer and P. von R. Schleyer, Adv. Organomet. Chem., 1985, 24, 353; (b) C. Schade and P. von R. Schleyer, Adv. Organomet. Chem., 1987, 27, 169; (c) R. E. Mulvey, Chem. Soc. Rev., 1991, 20, 167; (d) Z. Rappoport and I. Marek, The Chemistry of Organolithium Compounds, Wiley, New York, 2004; (e) R. A. Gossage, J. T. B. H. Jastrzebski and G. Van Koten, Angew. Chem., Int. Ed., 2005, 44, 1448.

9 (a) M. G. Davidson, C. L. Doherty, A. L. Johnson and M. F. Mahon, Chem. Commun., 2003, 1832; (b) S. D. Bull, M. G. Davidson, A. L. Johnson, M. R. Mahon and D. E. J. E. Robinson, Chem.-Asian J., 2010, 5, 612; (c) A. J. Chmura, M. G. Davidson, C. J. Frankis, M. D. Jones and M. D. Lunn, Chem. Commun., 2008, 1293; (d) A. J. Chmura, C. J. Chuck, M. G. Davidson, M. D. Jones, M. D. Lunn, S. D. Bull and M. F. Mahon, Angew. Chem., Int. Ed., 2007, 46, 2280.

10 (a) K. Ruhlandt-Senge, K. W. Henderson and P. C. Andrews, in Comprehensive Organometallic Chemistry III, ed. R. H. Crabtree and M. Mingos, 2007, ch. 1, vol. 2; (b) F. Pauer and P. P. Power, in Lithium Chemistry, ed. A. M. Sapse and P. Von R. Schleyer, Wiley Interscience, New York, London, Sydney, 1996, p. 295; (c) D. C. Bradley, R. C. Mehrotra, I. P. Rothwell and A. Singh, in Alkoxo and Aryloxo Derivatives of Metals, Academic Press, London, 2001.

11 M. Kol, M. Shamis, I. Goldberg, Z. Goldshmit, S. Alfi and E. HayutSalant, Inorg. Chem. Commun., 2001, 4, 177.

12 W. Huang, Z. Chu and F. Xu, J. Mol. Struct., 2008, 885, 154.

13 (a) L. Michalczyk, S. de Gala and J. W. Bruno, Organometallics, 2001, 20, 5547; (b) C. J. Whiteoak, B. Gjoka, E. Martin, M. M. Belmonte, E. C. Escudero-Adán, C. Zonta, G. Licini and A. W. Kleij, Inorg. Chem., 2012, 51, 10639.

14 T. J. Boyle, D. M. Pedrotty, T. M. Alam, S. C. Vick and M. A. Rodriguez, Inorg. Chem., 2000, 39, 5133.

15 See for example: (a) P. A. Van der Schaaf, J. T. B. H. Jastrzebski, M. P. Hogerheide, W. J. J. Smeets, A. L. Spek, J. Boersma and G. Van Koten, Inorg. Chem., 1993, 32, 4111; (b) W. J. Evans, R. E. Golden and J. W. Ziller, Inorg. Chem., 1993, 32, 3041; (c) M. Kunert, E. Dinjus, M. Nauck and J. Sieler, Chem. Ber., 1997, 130, 1461; (d) D. J. McDougall, B. C. Noll and K. W. Henderson, Inorg. Chem., 2005, 44, 1181; (e) W. Clegg, M. G. Davidson, D. V. Graham, G. Griffen, M. D. Jones, A. R. Kennedy, C. T. O'Hara, L. Russo and C. M. Thomson, Dalton Trans., 2008, 1295.

16 (a) D. M. Cousins, M. G. Davidson, D. García-Vivó and M. F. Mahon, Dalton Trans., 2010, 39, 8203; (b) B. Calvo, M. G. Davidson and D. García-Vivó, Inorg. Chem., 2011, 50, 3589.

17 A preferential $\mathrm{N}-\mathrm{H}$ deprotonation would be anticipated in view of the $\mathrm{p} K_{\mathrm{a}}$ values reported for related species $\left[\mathrm{p} K_{\mathrm{a}}=9.80\left(\mathrm{Me}_{3} \mathrm{NH}^{+}\right)\right.$, 10.86 (2,4,6-trimethylphenol)].

18 For 6 all the crystallizations yielded low-quality crystals which led to poor diffraction data. However, the crystallographic study allows for an unambiguous characterization of the structural motif.

19 (a) A. J. Nielson, C. Shen and J. M. Waters, Acta Crystallogr., Sect. C: Cryst. Struct. Commun., 2003, 59, m494; (b) J. D. Chartres, A. Dahir, P. A. Tasker and F. J. White, Inorg. Chem. Commun., 2007, 10, 1154. 20 L. O. Müller, R. Scopelitti and I. Krossing, Z. Anorg. Allg. Chem., 2008, 634, 1035. 